$\square$ Math-Net.Ru 
Общероссийский математический портал 
Л. Л. Сабинина, Об одной проблеме теории гладких луп, Матем. заметки, 2003, том 74, выпуск 6, 947-949

DOI: https://doi.org/10.4213/mzm605 
Использование Общероссийского математического портала Math-Net.Ru подразумевает, что вы прочитали и согласны с пользовательским соглашением http://www. mathnet.ru/rus/agreement 
Параметры загрузки:

IP: 35.173 .137 .237

26 апреля 2023 г., 03:51:43 


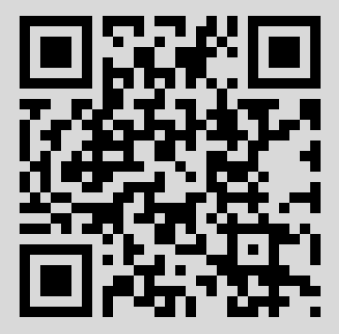




\section{ОБ ОДНОЙ ПРОБЛЕМЕ ТЕОРИИ ГЛАДКИХ ЛУП}

\section{Л. Л. Сабинина}

Эта статья посвящается Л. В. Сабинину к его семидесятилетию.

Геодезические лупы были введены Киккавой [1] и независимо Сабининым [2]. Это понятие можно также найти в $[3$, гл. 1] и [4]. Грубо говоря, геодезическая лупа - это пространство афффинной

Работа выполнена при поддержке PROMEP-SEP.

(C) Л.Л. САБининА

2003 
связности $(M, \nabla)$, наделенное локально бинарной операцией в точке $p$ по следующей формуле:

$$
u \underset{p}{u} v=\operatorname{Exp}_{u} \circ \tau_{p, u} \circ \operatorname{Exp}_{p}^{-1}(v)
$$

где $\operatorname{Exp}_{p}^{-1}: M \rightarrow T_{p}(M)$ - экспоненциальное отображение, а $\tau_{p, u}$ - параллельный перенос из точки $p$ в точку $u$ вдоль геодезической. Левые и правые трансляции этой бинарной операции являются гладкими локальными диффеоморфизмами, а точка $p$ - нейтральным элементом. Следовательно, бинарная операция (1) определяет локальную гладкую лупу. Легко видеть, что геодезическая лупа моноассоциативна, т.е. каждый элемент лупы порождает локальную подгруппу (геометрически геодезическую дугу) в лупе.

Естественньм образом возникает вопрос, который был предложен в книге [3] Акивисом: может ли произвольная гладкая моноассочиативная лупа быть реализована как геодезическая лупа некоторого пространства аффинной связности.

Изучая соответствия между геометрическими свойствами пространства афффинной связности $(M, \nabla)$ и алгебраическими свойствами геодезической лупы этого пространства, Сабинин ввел понятие геодезического одуля. Геодезическая лупа со скалярным произведением $u \rightarrow t_{p} u$ является геодезическим одулем (см. [4]), и при этом выполнено следующее условие: скалярное произведение $t_{p} u$ задает уравнение геодезической, которая проходит через точки $p$ и $u$, где $u$ - это точка в некоторой нормальной окрестности $N_{p}$ точки $p$, a $t$ - скалярный параметр.

Этот аппарат позволил Сабинину получить более полную информацию о структуре геодезических луп в разных точках пространства $M$. В частности, им были найдены необходимые и достаточные условия для того, чтобы одуль мог быть реализован как геодезический одуль некоторого пространства аффинной связности. Используя результаты работ [5], [4] по теории одулей и формулируя в эквивалентной форме для луп условие геометричности для одуля, мы получаем следующий результат.

ТЕоремА. Гладкая локальная моноассочиативная лупа может быть реализована как геодзическая лупа некоторого пространства аффинной связности тогда и только тогда, когда выполнено следующее условие:

$$
l_{x, a}\left(a^{n}\right)=\left(l_{x, a} a\right)^{n}, \quad n \in \mathbb{Z},
$$

əде $l_{x, a}=L_{x \cdot y}^{-1} \circ L_{x} \circ L_{a} u L_{a} b=a \cdot b$.

В частности, гладкая локальная моноассоциативная лупа с левым $A$-свойством $\left(l_{x}, a\right.$ являются автоморфизмами лупы) может быть реализована как геодезическая лупа; а также гладкая локальная правая моноальтернативная лупа (т.е. лупа, в которой выполнено соотношение $\left(x \cdot y^{m}\right) \cdot y^{n}=$ $\left.x \cdot y^{m+n}\right)$ может быть реализована как геодезическая лупа.

ЗАмечАниЕ. Существуют моноассоциативные лупы, не обладаюшие свойством геометричности (формула (2)). Например, функция двух комплексных переменных

$$
f(x, y)=\frac{-x y+3 x+3 y-1}{3 \bar{x} y-\bar{x}-y+3} \quad \text { для }|x|<1, \quad|y|<1
$$

определяет операцию такой лупы. 


\section{СПИСОК ЦИТИРОВАННОЙ ЛИТЕРАТУРЫ}

1. Kikkawa M. // J. Sci. Hiroshima Univ. Ser. A-I Math. 1964. V. 28. P. 199-207. 2. Сабинин Л. В. // Докл. АН СССР. 1977. Т. 233. № 5. C. 800-803. 3. Akivis M. A., Goldberg V. V. Differential Geometry of Webs // Handbook of Differential Geometry / ed. F. J. E. Dillen and L. C. A. Verstraelen. North-Holland, 2000. P. 1-152. 4. Sabinin L. V. Smooth Quasigroups and Loops: Kluwer Academic Press, 1999. 5. Сабинин Л. В. // Докл. АН СССР. 1995. Т. 344. №6. C. $745-748$. 